\title{
Myrmica sabuleti Workers Cannot Acquire Serial Recognition if not Rewarded
}

\author{
Marie-Claire Cammaerts ${ }^{1} \&$ Roger Cammaerts $^{2}$ \\ ${ }^{1}$ Independent researcher, retired from the Biology of Organisms Department, University of Brussels, Belgium \\ ${ }^{2}$ Independent researcher, retired from the Natural and Agricultural Environmental Studies Department (DEMNA) \\ of the Walloon Region, Belgium. \\ Correspondence: Marie-Claire Cammaerts, independent researcher, 27, Square du Castel Fleuri, 1170 Bruxelles, \\ Belgium. Tel: 322-673-4969. E-mail: mtricot@ulb.ac.be; mccammaerts@gmail.com
}

Received: May 24, 2018

doi:10.5539/ijb.v10n3p39
Accepted: June 4, 2018

Online Published: June 15, 2018

\begin{abstract}
Having previously found that workers of the ant Myrmica sabuleti can acquire serial recognition when rewarded after having walked a correct visual sequence, we here examined if they can acquire this type of learning (that is recognizing a correct sequence presented together with wrong ones) without being rewarded. Using the same colonies two months later and sequences made of four never previously presented elements, we observed that these ants could not significantly acquire serial recognition. Thereafter, rewarding the ants at each step (element) of the sequence, they could progressively acquire some serial recognition, reaching a score of $60 \%$ after seven training days. This score no longer increased the day after, being thus the maximum score the ants could reach. The ant $M$. sabuleti can thus acquire serial recognition only if duly rewarded during training. Moreover, on the basis of their responses to three wrong sequences during testing, it might be presumed that, when being rewarded at each element of the sequence and not at the end of it, the ants better memorize the first element of the sequence. These studies have demonstrated that ants, particularly the workers of M. sabuleti, can acquire serial recognition only through operant conditioning.
\end{abstract}

Keywords: learning, memory, operant conditioning, sequence, visual cue

\section{Introduction}

Learning and memorizing a behavioral sequence is an ability presented by sufficiently evolved animals. Some birds, monkeys and the humans of course have this ability (Pearce, 2008), which has been until now scarcely researched in invertebrates. There are several categories of sequence learning: serial recognition, response chaining, and simultaneous chaining. Examples in different animals are given in Pearce (2008). We recently approached this topic in the ant Myrmica sabuleti Meinert 1861. We first addressed response chaining, and showed that ants could learn a behavioral sequence when being rewarded at the end of the sequence, and that the last act of the sequence was better learned than the previous ones (Cammaerts M.-C. and Cammaerts R., 2018a). We then addressed serial recognition, and showed 1. that the ants could recognize a correct sequence made of three or four elements, given the choice between a correct and two or three wrong sequences, when being rewarded during the training, and 2. that the last element of the sequence was the best memorized (Cammaerts M.-C. and Cammaerts R., 2018b). At the end of the latter work, we presented six ideas for ongoing research on the subject, one of which appeared most pertinent: are ants able to acquire serial recognition if not rewarded while being trained?

The present work tempted to answer this question. Briefly, we aimed to present to the ants a sequence of four elements considered as the correct one, without rewarding them with any meat or sugar water or with the proximity of the nest entrance, and then to test these ants in front of the correct and three wrong sequences (first part of the study). We then (second part of the study) aimed to present to the ants a 'correct' sequence rewarding them at each element of the sequence, and after that to test the ants exactly as during the first part of the study. This study used sequence(s) of four elements fully different from the sequences used in our previous works (references above). Moreover, a period of two months elapsed between our last previous work (reference above) and the present one.

Below we explain how we selected the location of the sequences in the ants' foraging area, which sequences were used and how we built them, how we trained the ants once without a reward then rewarding them at each element 
of the sequence, and how we assessed their potential learning. We explain then discuss our results and finally show how the present work contributes to the subject.

\section{Material and Methods}

\subsection{Collection and Maintenance of Ants}

The work was made on two colonies of M. sabuleti Meinert 1861 collected in May 2017, at Rédange (France, Moselle Department). The colonies contained about 500 workers, brood and one queen. Each one was maintained in glass tubes half filled with water, a cotton plug separating the ants from the water. The tubes of each colony were deposited in a tray $(34 \mathrm{~cm} \times 23 \mathrm{~cm} \times 4 \mathrm{~cm})$, the borders of which were covered with talc. The ants received $a d$ libitum an aqueous solution of sugar provided in a small cotton plugged tube, and three times a week, cut Tenebrio molitor (Linnaeus, 1758) larvae. The air temperature equaled $20-21^{\circ} \mathrm{C}$ and the relative humidity about $80 \%$. The intensity of lighting equaled 330 lux while working on ants and 5-120 lux during other time periods, and the electromagnetic field was of $2-3 \mu \mathrm{W} / \mathrm{m}^{2}$. The workers are in this study often referred to as "nestmates", as commonly done by researchers on social insects.

\subsection{Localization of the Sequences Presented to the Ants}

Since at first (Experiment 1) the ants should not be rewarded, the sequences were not set in front of the nest entrances or of the food sites. Where should the sequences be located? To answer this question, we criss-crossed the foraging area of the two used colonies (i.e. the area lying between the nest and the food sites), as shown in Figure 1, upper part. We then recorded, for each colony, the trajectories of 40 foragers reproducing them on a paper criss-crossed exactly as the ants' area, and we measured the length (in cm, using a curvimeter) of the trajectories travelled in each square $(3 \mathrm{~cm} \times 3 \mathrm{~cm})$ of the grid pattern. For each square, we added the length of all the trajectories walked on it, and we obtained the numbers given in Figure 1, upper part. We then looked for two places measuring $1.5 \mathrm{~cm} \mathrm{x} 4 \mathrm{~cm}$ (= the dimensions of a sequence) not oriented towards the nest or a food site, where the total length of the walked trajectories was maximum, i.e. where the ants' traffic was maximum. The two places we found for colony A and colony B differed only slightly (Figure 1, upper part).

Subsequently (Experiment 2, performed one week after the Experiment 1), the ants should be rewarded at each element of the sequences. We did so by removing their meat and sugar food, and by depositing, on a cover glass slide (24 mm x $50 \mathrm{~mm}$ ) set aside the sequences, a small drop of 50\% diluted concentrated sugared milk (Nestlé $\left.{ }^{\circledR}\right)$ aside each of the four elements of each sequence. This is schematized in Figure 1, lower part and is shown in Figure 3D.

\subsection{Construction of the Sequences}

Two identical sequences (see Figure 1, and 3A) were constructed for each colony, each of them being made of four elements (Figure 2, left part). Each element was tied to a support consisting of a piece of white extra strong paper (Steinbach ${ }^{\circledR}$ ) vertically maintained, its base being tied to a horizontal piece of white paper in order to be held in place with the three other elements during the entire experimental time period. The dimensions of the elements, their support, and a whole sequence are shown in Figure 2. The four elements, made of colored strong paper (Clairefontaine $\left.{ }^{\circledR}\right)$, were placed in the following correct order (the order the ants should learn): a square, a '+', a circle, and a ' $\mathrm{x}$ ', successively (Figure 2).

After the ants were trained during four days (see the paragraph just below), they were tested (see the second paragraph below) in a tray devoted only to test $(15 \mathrm{~cm} \times 30 \mathrm{~cm} \times 4 \mathrm{~cm}$, each colony having its own tray) into which four different sequences had been set. These sequences were the correct one (square, + , circle, $x$ ), the wrong one 'square,,$+ \mathrm{x}$, circle' the two first elements of which being correct, another wrong one ' $\mathrm{x},+$, circle, square' the second and the third elements of which being correct, and a further wrong one '+, square, circle, $x$ ' the two last elements of which being correct (see these four sequences in Figure 2, right part). A photo of the entire experimental design is shown in Figure 3A. 


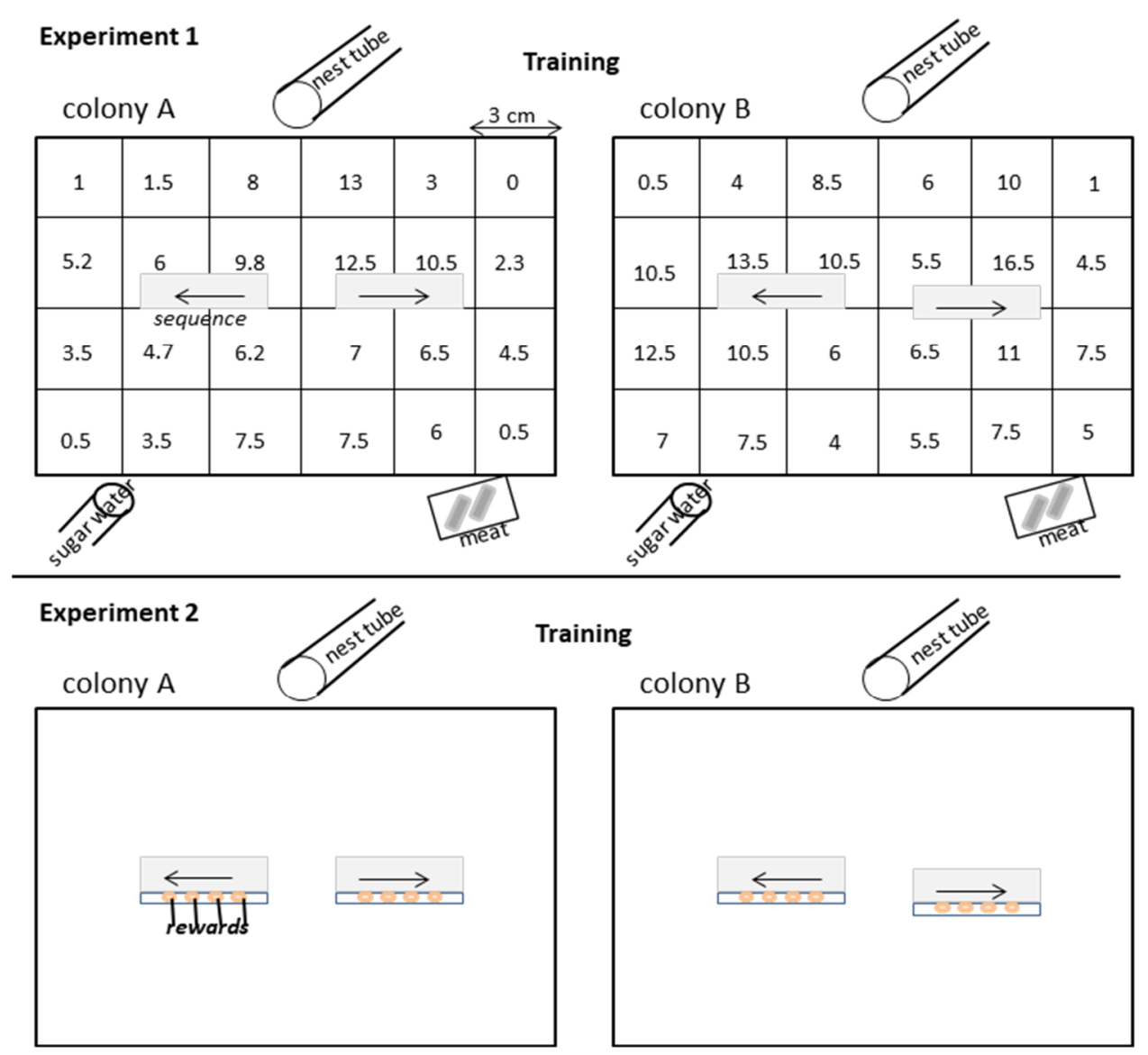

Figure 1. Localization of the sequence of four elements presented to trained ants being not rewarded (Experiment 1), or being rewarded aside each element (Experiment 2). For being not rewarded, the ants had to see the sequence elsewhere than on their way to their nest entrance or food sites. The sequences were thus deposited in the foraging area according to another orientation and where the ants' traffic was the most intense. This traffic was quantified by the sum, in centimeter, of the trajectories travelled in each square of the gridded foraging area bottom (presented under 'Experiment 1'). During the Experiment 2, the ants were rewarded with droplets of sugared milk set aside each element of the sequences (orange circles). The arrow on each sequence indicates its orientation, from its first to its fourth element
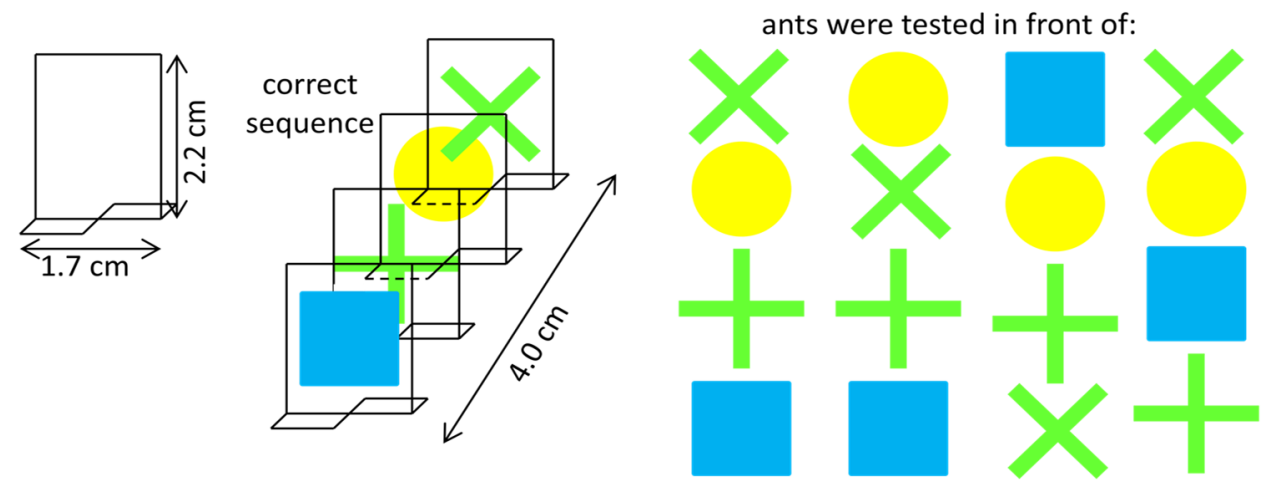

Figure 2. Visual sequences presented to ants during training and testing. The construction of each part of the sequences and their assembly are explained in the 'Material and Methods' section. During training, the ants received one kind of sequence, considered as the 'correct' one. During testing, they received four kinds of sequences made of the same elements, but otherwise ordered. If the ants were able to memorize the 'correct' sequence, they would be more numerous on that sequence than on the other ones. The tests were performed over

four training days (Days 5 to 8 ) following the first four training days, the ants being either not rewarded

(Experiment 1) or rewarded aside each element of the 'correct' sequence (Experiment 2) 

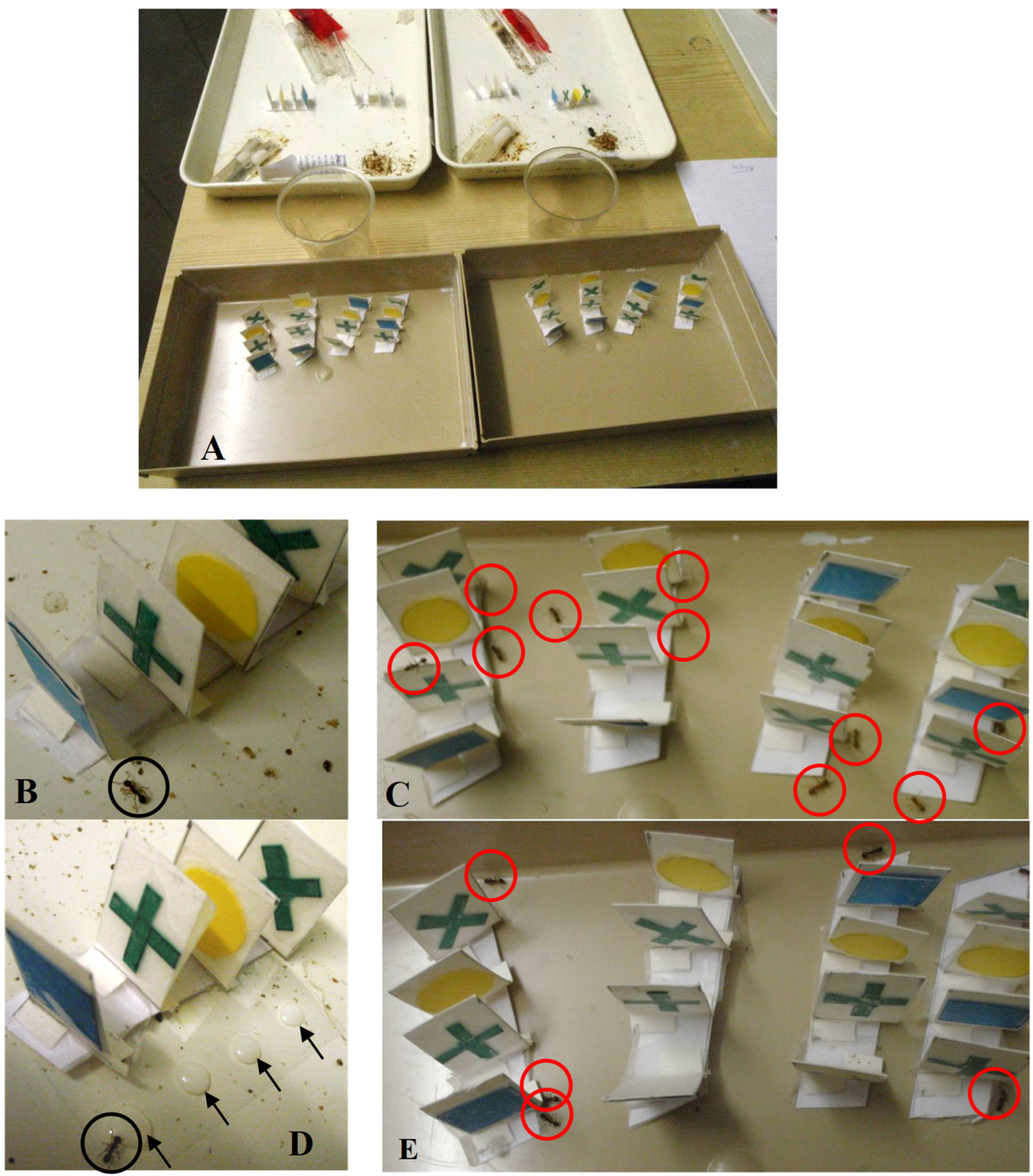

Figure 3. A. The entire experimental design. On the background: the ants' training in their foraging area; on the foreground: the trays devoted to testing with the four kinds of sequence; in the middle distance: the two glasses allowing removing and transferring 30 ants of each colony in their tray to perform a test. B. An ant under training without reward (black circle). C. Ants, trained without a reward, responding in the course of a test (red circles): they were not more numerous on the correct sequence (the most left one) than on the other ones $(3 v s 3,2,2)$. D. An ant (black circle) trained with a reward; it is drinking sugared milk (the four droplets of which are arrowed) while in sight of the correct sequence. E. Ants (red circles), trained with reward, responding in the course of a test: they were more numerous on the correct sequence (the most left one) than on the other ones $(3 v s 0,1,1)$

\subsection{Training the Ants}

When ants were not rewarded (Experiment 1) as well as, one week later, when they were rewarded (Experiment 2), during four days, six times per day, the ants of colony A and colony B present on or very near the two presented sequences were counted and the total of the $6 \times 2=12$ counts was established (Tables 1,2, upper part, second column $=$ daily sums). Finally, the average of all the counts was calculated (sum of the four daily sums $/ 12 \times 4$ ) (Tables 1, 2, upper part, third column). We so obtained the mean number of ants of colony A + B present at any time on or very near the correct sequence these ants should learn. 
Table 1. Experiment 1: Serial recognition by ants not rewarded during training

\begin{tabular}{|c|c|c|c|c|c|c|}
\hline Training & \multicolumn{4}{|c|}{ Total number of ants on the correct sequence } & \multicolumn{2}{|c|}{ mean/day and average number of ants } \\
\hline Day 1 & \multicolumn{2}{|c|}{$2+3+2+2+3+2+$} & $2+3+2+3+2+2$ & $=28$ & 2.33 & \multirow{4}{*}{1.88} \\
\hline Day 2 & $2+2+2+1$ & $-1+3+$ & $1+1+2+2+2+2$ & $=21$ & 1.75 & \\
\hline Day 3 & $2+2+1+1$ & $-1+2+$ & $3+2+1+2+2+2$ & $=21$ & 1.75 & \\
\hline Day 4 & $2+3+2+1$ & $-1+1+$ & $2+2+1+2+2+1$ & $=20$ & 1.67 & \\
\hline \multirow[t]{2}{*}{ Testing } & \multicolumn{4}{|c|}{ Total number and $\%$ of ants on the 4 sequences } & \multirow{2}{*}{\multicolumn{2}{|c|}{ random number on each sequence and $P$-value of the results }} \\
\hline & $\mathrm{s}+\mathrm{cx}$ & $\mathrm{s}+\mathrm{xc}$ & $\mathrm{x}+\mathrm{cs}$ & $+\operatorname{scx}$ & & \\
\hline Day 5 & 10732.0 & 7020.9 & 7823.4 & 7923.6 & 83.5 & $0.05<P<0.10$ \\
\hline Day 6 & 7328.6 & 7127.8 & 6425.1 & 4718.4 & 63.8 & $0.05<P<0.10$ \\
\hline Day 7 & 5930.6 & 4422.8 & 5126.4 & 3920.2 & 48.3 & $0.10<P<0.20$ \\
\hline Day 8 & 5830.9 & 4222.3 & 4926.1 & 3920.7 & 47.0 & $0.10<P<0.20$ \\
\hline
\end{tabular}

The ants were trained during eight days to a sequence of four elements without receiving any reward. They were tested at days 5, 6, 7 and 8 in front of that (correct) sequence and three other wrong ones. The ants' traffic on the sequence was assessed during training (upper part of the table), and their response to the four presented sequences was assessed during testing (lower part of the table). Experimental details and statistics are given in the text. Briefly, the correct sequence was ' $\mathrm{s}+\mathrm{cx}$ ', and the ants were not more numerous along it than along the three other wrong sequences. $\quad \mathrm{s}+\mathrm{cx}$ etc $\ldots=\mathrm{a}$ sequence, with $\mathrm{s}=$ a square, $+=\mathrm{a}^{\text {' }}+$ ', $\mathrm{c}=\mathrm{a}$ circle, $\mathrm{x}=\mathrm{a}$ ' $\mathrm{x}$ '.

Table 2. Experiment 2: Serial recognition by ants duly rewarded during training

\begin{tabular}{|c|c|c|c|c|c|c|}
\hline \multirow{2}{*}{$\begin{array}{l}\text { Training } \\
\text { Day } 1\end{array}$} & \multicolumn{4}{|c|}{ Total number of ants on the correct sequence } & \multicolumn{2}{|c|}{ mean/day and average $n^{\circ}$ of ants } \\
\hline & \multicolumn{3}{|c|}{$2+1+1+1+1+1+4+4+5+5+6+6$} & $=37$ & 3.08 & \multirow{4}{*}{1.92} \\
\hline Day 2 & $2+1+1+1$ & $-2+1+$ & $1+1+1+1+1+1$ & $=14$ & 1.17 & \\
\hline Day 3 & $1+1+2+1$ & $-1+2+$ & $1+1+1+2+1+2$ & $=16$ & 1.33 & \\
\hline Day 4 & $1+1+2+2$ & $-2+1+$ & $2+2+1+1+2+2$ & $=19$ & 1.58 & \\
\hline \multirow[t]{2}{*}{ Testing } & \multicolumn{4}{|c|}{ Total number and $\%$ of ants on the 4 sequences } & \multirow{2}{*}{\multicolumn{2}{|c|}{ random $\mathrm{n}^{\circ}$ on each sequence and $P$-value of the results }} \\
\hline & $\mathrm{s}+\mathrm{cx}$ & $\mathrm{s}+\mathrm{xc}$ & $\mathrm{x}+\mathrm{cs}$ & $+\operatorname{scx}$ & & \\
\hline Day 5 & 8549.1 & 2916.8 & 3017.3 & 2916.8 & 43.3 & $P<0.001$ \\
\hline Day 6 & 8952.9 & 2917.3 & 2514.9 & 2514.9 & 42.0 & $P<0.001$ \\
\hline Day 7 & 10260.4 & 2514.8 & 2213.0 & 2011.8 & 42.3 & $P<0.001$ \\
\hline Day 8 & 11258.6 & 3116.2 & 2312.0 & 2513.9 & 47.8 & $P<0.001$ \\
\hline
\end{tabular}

The legend is identical to that of Table 1, except that the ants were rewarded, during training, at each element of the correct sequence, and that they acquired some serial recognition, increasing their score over about seven days, reaching then a score of about $60 \%$.

\subsection{Testing the Ants}

The ants' testing made during the Experiment 1 (ants not rewarded) and the Experiment 2 (ants rewarded, one week later) must be identical in order to significantly compare the results of these two experiments. Each time, four successive tests were performed on the ants of colonies A and B, in the course of their $5^{\text {th }}, 6^{\text {th }}, 7^{\text {th }}$, and $8^{\text {th }}$ training days. Photos of these tests are shown in Figure 3. For each test, 30 ants were transferred in their tray devoted to test, and the ants present on or very near each sequence were counted 30 times during $15 \mathrm{~min}$, i.e. at the end of each 30 seconds time period. The numbers obtained for each colony were added, and treated separately for each kind of presented sequences. This gave, for experiment 1 and 2, the numbers (and from them, the proportions) of ants visiting each of four kinds of sequences, over four successive days (Tables 1,2, lower part). The four numbers of ants obtained at each of the four testing days were each time compared to those expected if ants visited randomly each four sequences using the non-parametric goodness of fit $\chi^{2}$ test (Siegel \& Castellan, 1989). 


\section{Results}

\subsection{Experiment 1}

\subsubsection{Training}

The number of ants moving on or very near the presented sequences was relatively low since they were not rewarded while doing so (Figure 3B). Nevertheless, the number of ants present at any time on the presented correct sequences was between 2.33 and 1.67 (meanly of 1.88 ants/day, Table 1, upper part). The ants tended to stop from time to time, and obviously saw well the four elements of the sequence. They had thus the possibility of memorizing (using their visual memory) the correct sequence of four elements.

\subsubsection{Testing}

During each test, made in the course of four days, the ants were slightly more numerous on the correct sequence than on the other ones (Figure 3C; Table 1, lower part). However, this difference was not statistically significant, though approaching significance. Indeed, for the first test (Day 5) $\chi^{2}=7.77, \mathrm{df}=3,0.05<\mathrm{P}<0.10$, for the second test (Day 6) $\chi^{2}=6.56, \mathrm{df}=3,0.05<\mathrm{P}<0.10$, for the third test (Day 7) $\chi^{2}=4.69, \mathrm{df}=3,0.10<\mathrm{P}<0.20$ and for the fourth test (Day 8) $\chi^{2}=4.55, \mathrm{df}=3,0.10<\mathrm{P}<0.20$. These results allowed the assumption that ants were, at the beginning of the test session, a little accustomed to the kind of sequence set in their foraging area (= the correct sequence), then in the course of the four tests, they recognized also, to a lesser extent, the three wrong sequences they saw while being tested. However, as a matter of fact, they acquired no efficient serial recognition in the course of their eight training days.

\subsection{Experiment 2 (Made One Week Later)}

\subsubsection{Training}

During their first training day, the ants were more numerous near the presented correct sequences, but were in fact consuming the newly discovered sugared milk (Table 2, upper part). Thereafter, they were less numerous in doing so, probably because this new food was very caloric. In the course of the four training days, a mean number of 1.92 ants was present at any time on and very near the correct sequences (Figure 3D; Table 2, upper part). The four daily mean numbers of ants on the correct sequences obtained while rewarding them (Experiment 2) did not statistically differ from those previously obtained when not rewarding them (Experiment 1) $(\mathrm{N}=4, \mathrm{~T}=+4,-6, \mathrm{P}=0.438)$. Consequently, if some difference appeared during the test experiments between the ants rewarded during training and those then not rewarded, this will not be due to a different ants' traffic in the vicinity of the correct sequences during training.

\subsubsection{Testing}

Let us recall that testing was performed from the ants' fifth until eighth training days. As soon as Day 5, the tested ants were more numerous on and near the correct sequence than on the other ones (Table 2, lower part, line 1), which was statistically significant $\left(\chi^{2}=48.66\right.$, df $\left.=3, \mathrm{P}<0.001\right)$. The three wrong sequences were visited by equivalent numbers of ants (Table 2, lower part, line 1, column 2). At their sixth training day, the tested ants were a little more inclined to move on and near the correct sequence than at their fifth day (Table 2, lower part, line $2 \mathrm{vs}$ line $1 ; 52.9 \%$ vs $49.1 \%$ ). They moved more around that correct sequence than around the three wrong ones (Figure $3 \mathrm{E}$ ), and this was statistically significant $\left(\chi^{2}=70.37, \mathrm{df}=3, \mathrm{P}<0.001\right)$ with a value of $\chi^{2}$ higher than that obtained the previous day (70.37 vs 48.66). Similarly to what occurred the previous day, the ants were equally numerous on and near the three wrong sequences (Table 2, lower part, line 2). After having been trained for seven days, during the afternoon of that seventh day, the tested ants moved more often all along the correct sequence than along the three other ones, reaching a score of about $60 \%$ (Table 2, lower part, line 3 ). This difference was statistically significant $\left(\chi^{2}=112.78, \mathrm{df}=3, \mathrm{P}<0.001\right)$. During this test, the ants moved a little more along the sequence $\mathrm{s}+\mathrm{xc}$ (the two first elements of which were correct) than along the two other wrong sequences, but this observation was not at all statistically significant $\left(\chi^{2}=0.36, \mathrm{df}=3,0.80<\mathrm{P}<0.90\right)$. When reaching their eighth training day, the tested ants again moved more often along the correct sequence than along the other ones, but they did so no more than during their seventh training day. It appeared as if the ants' learning was reaching a plateau. Of course, the ants' higher locomotion along the correct sequence was statistically significant $\left(\chi^{2}=115.83, \mathrm{df}=3, \mathrm{P}<\right.$ $0.001)$, and the $\chi^{2}$ value was this time similar to that obtained the day before (115.83 vs 112.78). Like it happened at their seventh day, during their eighth training day, the tested ants moved a little more often along the sequence $\mathrm{s}+\mathrm{xc}$ than along the two other wrong sequences. This difference was not significant $\left(\chi^{2}=1.31, \mathrm{df}=2, \mathrm{P} \sim 0.50\right)$ with, however, a higher $\chi^{2}$ value than at the seventh day $\left(\chi^{2}=1.31\right.$ vs $\left.\chi^{2}=0.36\right)$. 


\section{Discussion}

In the present work, we showed that ants could not acquire serial recognition (i.e. recognize a correct sequence between that sequence and three wrong ones) when not rewarded, despite having been provided for eight days with the correct sequence. We also showed that the ants could very obviously acquire serial recognition when receiving some reward together with the correct sequence during about four days, even reaching a maximum score of $60 \%$ after 7 training days. These results agreed with two previous ones according to which the ants could perform a behavioral sequence (Cammaerts \& Cammaerts, 2018a) and recognize a correct sequence (Cammaerts \& Cammaerts, 2018b) when the correct sequences were located during training in front of the nest or the sugar tube entrance, thus when being rewarded after having performed or moved along the sequence. The here shown ants' serial recognition acquisition is thus, finally an operant conditioning. Let us be precise that this statement concerns the studied species M. sabuleti. As usually, for such a conditioning, at least for the used species, the ants' score increased during a few days, then reached a never exceeded level (in the present work on serial recognition with four elements, this level equaled $60 \%$ ).

On the basis of the ants' responses to the three wrong sequences presented during the tests (they progressively responded slightly better to the sequence the two first elements of which were correct), it might be presumed that, when rewarded all along the sequence (present work) and not at the end of it (Cammaerts \& Cammaerts, 2018b), the ants better memorized the first element of the sequence than the other ones.

Serial recognition has scarcely been examined in invertebrates, including insects (Pearce, 2008). Nearly all the studies on this topic were performed on humans, monkeys and rats (Pearce, 2008).

Few studies concern the individuals' behavior. Let us quote three of them. Sands and Wright (1980) showed that a rhesus monkey produced a learning curve similar to that of a human aged of 22 years, this encouraging the view of similar mechanisms of memory in monkeys and humans. Pineda, Herrera, Kang and Sandler (1998) proved that smoking (i.e. nicotine) facilitates some memorization. Let us add that bees' memory is enhanced by nicotine (Døring \& Chittka, 2011), and that ants under a nicotine diet reached a high conditioning score if rewarded by nicotine, but learned nothing if rewarded as usually by sugar water (Cammaerts, Gosset \& Rachidi, 2014). Farrell and McLaughlin (2007) demonstrated a dissociation between ordinal and temporal information during a short-time memorization.

Most of the studies approaching the present subject are physiological ones. They concern, among others, the response of neurons, the role of the hippocampus, and the impact of brain damage, three themes here below illustrated. The response of single neurons has been examined, for instance, by Baylis and Rolls (1987) and, in the macaque, by Rolls, Cahusac, Feigenbaum and Miyashita (1993), what revealed the importance of particular parts of the brain. The role of the perirhinal cortex and the hippocampus has again been demonstrated by Brown and Aggleton (2001). Visual pattern memory and serial recognition task have been examined following damage (excisions) in particular brain zones, revealing so the role of these zones (Brown \& Aggleton, 2001).

Similar physiological studies on ants are becoming possible. These insects can be attached and visually (or olfactorily) stimulated, and the functioning of their brain can be observed, at least to some degree of precision, this allowing detection which part (not yet which neurons) of the brain accomplishes given neuronal functions. The technique underlying such studies is presently being ameliorated by Fernandes, Buckley and Niven (personal communication). No doubt that, on the basis of behavioral and physiological studies, humans will finally know which parts of the insect's brain accomplish given functions, and ants are promising models to attempt reaching this aim.

\section{Conflict of interest}

We affirm having no conflict of interest when conducting our research on ants' cognitive abilities, and using them as biological models. We receive no money for making our research.

\section{References}

Baylis, G. C., \& Rolls, E. T. (1987). Responses of neurons in the inferior temporal cortex in short term and serial recognition memory tasks. Experimental Brain Research, 65(3), 614-622. https://doi.org/10.1007/ BF00235984

Brown, M. W., \& Aggleton, J. P. (2001). Recognition memory: What are the roles of the perirhinal cortex and hippocampus? Nature Reviews Neuroscience, 2, 51-61. https://doi.org/10.1038/35049064 
Cammaerts, M. C., Gosset, G., \& Rachidi, Z. (2014). Some physiological and ethological effects of nicotine; studies on the ant Myrmica sabuleti as a biological model. International Journal of Biology, 6, 64-81. https://doi.org/10.5539/ijb.v10n2p31

Cammaerts, M.-C., \& Cammaerts, R. (2018a). Learning a behavioral sequence: an accessible challenge for Myrmica sabuleti workers? International Journal of Biology, 10(2), 1-14. https://doi.org/10.5539/ijb.v10n2p1

Cammaerts, M.-C., \& Cammaerts, R. (2018b). Ants can acquire some serial recognition. International Journal of Biology, 10(2), 23-32. https://doi.org/10.5539/ijb.v10n2p31

Døring, T. D., \& Chittka, L. (2011). How human are insects and does it matter? Formosan Entomologist, 31,85 99. chittkalab.sbcs.qmul.ac.uk/Pub.html

Farrell, S., \& McLaughlin, K. (2007). Short-term recognition memory for serial order and timing. Memory \& Cognition, 35(7), 1724-1734. https://doi.org/10.5539/ijb.v10n2p31

Owen, A. M., Sahakian, B. J., Semple, J., Polkey, C. E., \& Robbins, T. W. (1995). Visuo-spatial short-term recognition memory and learning after temporal lobe excisions, frontal lobe excisions or amygdalo-hippocampectomy in man. Neuropsychologia, 33(1), 1-24. https://doi.org/10.5539/ijb.v10n2p31

Pearce, J. M. (2008). Animal learning and cognition, an introduction. East Sussex, USA, Canada. Psychology Press. http://www.worldcat.org/title/animal-learning-cognition-an-introduction/oclc/682223995

Pineda, J. A., Herrera, C., Kang, C., \& Sandler, A. (1998). Effects of cigarette smoking and 12-h abstention on working memory during a serial-probe recognition task. Psychopharmacology, 139(4), 311-321. https://doi.org/10.1007/s002130050722

Rolls, E. T., Cahusac, P. M. B., Feigenbaum, J. D., \& Miyashita, J. (1993). Responses of single neurons in the hippocampus of the macaque related to recognition memory. Experimental Brain Research, 93(2), 299-306. https://doi.org/10.1007/BF00228398

Sands, S. F., \& Wright, A. A. (1980). Serial probe recognition performance by a rhesus monkey and a human with 10- and 20-item lists. Journal of Experimental Psychology: Animal Behavior Processes, 6(4), 386-396. http://dx.doi.org/10.1037/0097-7403.6.4.386

Siegel, S., \& Castellan, N. J. (1989). Nonparametric statistics for the behavioural sciences. Singapore: McGraw-Hill Book Company. Retrieved from https://www.amazon.com/Sidney-Siegel...Statistics.../ B008WDIR6

\section{Copyrights}

Copyright for this article is retained by the author(s), with first publication rights granted to the journal.

This is an open-access article distributed under the terms and conditions of the Creative Commons Attribution license (http://creativecommons.org/licenses/by/4.0/). 